\title{
OS PERIÓDICOS LITERÁRIOS: REGISTRO, ACERVO E MEMÓRIA
}

\author{
LITERARY JOURNALS: RECORD, ARCHIVE AND MEMORY \\ Enviado em 9 de março de 2015 \\ Aceito em 26 de abril de 2015 \\ Carla Renata Antunes de Souza Gomes ${ }^{1}$
}

\begin{abstract}
Resumo: $O$ artigo a seguir apresenta reflexões sobre a constituição de um duplo acervo documental, o primeiro relativo aos documentos publicados nos periódicos, de coleções públicas ou particulares, e o segundo referente à produção periodística dedicada ao cultivo da memória e da história da Província. Discute sobre o duplo estatuto da memória arquivada nesses periódicos, da memória das práticas letradas, da formação de associações literárias, do exercício do debate e da crítica, da troca de experiências, do estímulo à leitura e à troca de ideias, da interdição aos eventos em torno da guerra civil e alguns de seus personagens. $O$ acervo produzido pelos periódicos permite acompanhar o esforço empreendido para a realização de narrativas sobre a Revolução e a superação dos obstáculos para empreendê-las.
\end{abstract}

Palavras-chave: Memória. Periódicos literários. Acervo documental.

Abstract: The following article reflects on the formation of document archives that serve two purposes. The first purpose relates to documents published in journals that are housed in public or private collections. The second is regarding the production of journalism dedicated to cultivating the memory and history of the Province. This article discusses the dual role of the historical memory archived in these journals. It also discusses memory of literary practices, formation of literary societies, the realization of debate and criticism, the exchange of experiences, the promotion of reading and the exchange of ideas, as well as the involvement in events related to the Civil War and some of its protagonists. The archives produced by the journals allow the reader to accompany the efforts made to create narratives about the Revolution and overcome obstacles that inhibited the creation of those narratives.

Keywords: Memory. Literary journals. Document archive.

${ }^{1}$ Museóloga e Doutora em História pela Universidade Federal do Rio Grande do Sul. Professora de graduação em História e de pós-graduação no Mestrado de Memória e Bens Culturais da UNILASALLE Canoas. E-mail: renata.asg@terra.com.br 
O artigo a seguir apresenta parte da reflexão desenvolvida na tese Entre Tinteiros e Bagadus: memórias feitas de sangue e tinta. A escrita da história em periódicos literários porto-alegrenses do século XIX (1856-1879), sobre a constituição de um duplo acervo documental, o primeiro relativo aos documentos publicados nos periódicos, pertencentes às coleções públicas ou particulares, e o segundo referente à produção periodística dedicada ao cultivo da memória e da história da Província, assim como discute sobre o duplo estatuto da memória arquivada nesses periódicos, isto é, a memória das práticas letradas, em torno da escrita pública, da formação de associações literárias, do exercício do debate e da crítica, da troca de experiências, do estímulo à leitura e à troca de ideias, e a memória da emergência da cultura histórica, sobretudo, da interdição aos eventos em torno da guerra civil e alguns de seus personagens, nesse particular, o acervo produzido pelos periódicos permite acompanhar o esforço empreendido para a realização de narrativas sobre a Revolução e a superação dos obstáculos para empreendê-las.

Existem ainda muitas possibilidades de indagação aos periódicos, a fim de procurar perceber as relações entre literatura, história/historiografia num espaço compartilhado por ambas que constrói sentidos e significados sobre a cultura regional e em que medida seus discursos se entrelaçam, se complementam ou se distanciam na produção de um imaginário social sobre os rio-grandenses. Esse é apenas um veio de uma imensa jazida a ser explorada.

Em 7 de setembro de 1856, na edição de n.6, O Guayba. Periódico Semanal, Litterario e Recreativo, fundado há apenas um mês na capital, e "querendo finalmente promover a cultura de um ramo de literatura ainda quase desconhecido em nossa Província" realiza um concurso de biografias e oferece um prêmio de 50 mil réis "para a melhor biografia de um desses homens que se distinguiram na Província" 2 , tal proposição, entretanto não encontrou acolhida entre os letrados locais. Então, na edição de 28 de junho de 1857, os redatores informam que "talvez por causa da dificuldade de escrever sobre a vida de homens distintos, cujas famílias ainda existem" o concurso de biografias não obteve o sucesso desejado. Não obstante, publicam nessa edição "um documento que foi transmitido pelo Exmo. Sr. General Gabriel d'Araújo e Silva" a fim de "arquivar o mais possível notícias que possam mais tarde servir à pena que quisesse escrever a história de nossa Província". ${ }^{3}$

Embora a ausência de inscritos não signifique a inexistência de pessoas habilitadas a escreverem "sobre a vida dos homens distintos" da Província, ela indica a

\footnotetext{
2 Suplemento ao n. 6 d'O Guayba. In: O Guayba, 07 de setembro de 1856, ano 1, n.6, p.s/n.

${ }^{3}$ O GUAYBA, 28 de junho de 1857, ano 2, n.26, p.202.
} 
efetiva dificuldade de escrita de histórias que podiam exigir posicionamentos e julgamentos políticos. Ainda assim, contrariando as expectativas mais pessimistas, o periódico publica nas edições n.8 e 9, em setembro, e n.11, em outubro de 1856, as biografias de José Feliciano Fernandes Pinheiro e Gaspar Francisco Menna Barreto, escritas por colaboradores do periódico.

Deve-se, portanto destacar o empenho dos redatores em trazer ao público leitor informações que servissem a quem se habilitasse a escrever sobre a história da Província, bem como as ações culturais promovidas no intuito de envolver a sociedade letrada no esforço de produzir matérias de interesse da Província.

O GUAYBA. Periódico Semanal, Litterario e Recreativo, é o primeiro periódico dedicado exclusivamente à vida cultural da cidade de Porto Alegre, circulou sempre aos domingos de 03 de agosto de 1856 a 26 de dezembro de 1858 e publicou 120 exemplares. Durante esse período de tiragem semanal apenas 05 números não são impressos e 05 exemplares de 1857 não foram encontrados para consulta.

Além das Biographias de Rio-Grandenses ilustres pelas Ciências, Letras, Armas e Virtudes, nossa análise concentra-se ainda nos temas relativos a história do Rio Grande do Sul, com destaque para a guerra civil, presentes no artigo de opinião ou "de fundo" que aborda temas bastante variados, entre os mais constantes estão: Filosóficos (22), Religiosos (18), de História geral e do Brasil (18), Educação (12), Literatura (12), Imprensa (10), os demais (22) abordam geografia e geologia, crítica social, imigração, artes, mulher, classe militar e o Futuro. ${ }^{4}$ Tal seleção de assuntos estabelece relações necessárias com um público leitor que devia provir em grande parte do ensino secundário, formado tanto por alunos quanto por professores, assim os temas correspondem de uma parte às matérias lecionadas e de outra aos temas de formação do cidadão, ou seja, as críticas ao sistema de ensino, a seleção e má remuneração dos professores, aos costumes da sociedade, ao papel da mulher e, principalmente sobre a importância da imprensa para a sociedade.

Antes da apresentação da Revista do Instituto Histórico e Geográfico da Província, o segundo periódico a orientar essa investigação, faz-se necessário um breve comentário sobre as dificuldades enfrentadas, nesse tempo, pelos que se dispunham a publicar matérias relativas à guerra civil rio-grandense.

\footnotetext{
4 Para cumprir seus objetivos $O$ Guayba mantém algumas seções permanentes, além do artigo de opinião ou "de fundo", o Álbum Poético e a Revista. Outras seções, como Biographias de Rio-Grandenses ilustres pelas Ciências, Letras, Armas e Virtudes, Contos, Variedades, Romance, Anedotas, Romances e Novelas, Cosmorama, Reflexões Cosmographicas e Retratos Históricos do Século XIX, flutuarão em suas páginas conforme as contribuições dos colaboradores. São bastante variados os assuntos abordados pelo artigo de opinião.
} 
Entre 1858 e 1865 circulou em Pelotas, de terça-feira a domingo, O Brado do Sul, periódico que gerou muitas controvérsias, primeiro, conforme Guilhermino Cesar (1958, p.175 apud SILVA, 1986, p.142), pelo modo franco com que seu diretor Karl Von Koseritz abordava os assuntos políticos e, em seguida, pela disposição de Domingos José de Almeida, que assumiu a direção do jornal, em publicar documentos sobre a República farroupilha e em escrever sobre a história da revolução que, segundo Menegat "foi adiada por pedidos tanto dos aliados quanto dos adversários" (2009, p.167) $)^{5}$

Tais dificuldades são relatadas por Almeida, em correspondências a antigos companheiros da guerra como o Tenente-coronel Manuel Antunes da Porciúncula, o General Antonio de Souza Neto e o Coronel Manuel Lucas de Oliveira, durante o ano de 1859, nas quais reitera a intenção de "escrever a história da "epopeia farroupilha" para as gerações futuras", assim como revela as acusações que sofre dos que se opõe a essa ideia (FIGUEIREDO, 2000, p.76-77). As cartas revelam também incentivadores do projeto como o Coronel José Pinheiro de Ulhoa Cintra, para o qual "o tempo não pode ser mais próprio, quando já decorreram mais de 15 anos depois da pacificação", além disso, sobre as resistências e combates ao projeto indaga: "que mal proveio ao Brasil de terem historiadas as revoluções de Minas e Pernambuco logo depois do drama que ali se representou?"6(FIGUEIREDO, 2000, p.84).

Sobre as mal cicatrizadas feridas no orgulho dos rio-grandenses farroupilhas, de então, cabe destacar um trecho da carta de Domingos José de Almeida a Manuel Antunes da Porciúncula em outubro de 1859, na qual comenta suas dificuldades na escrita da história da revolução e de sua "obrigação"7 com a memória de Bento Gonçalves, relembra o clima de insatisfação entre aqueles que participaram da guerra e foram "indultados" pelo Imperador a fim de conservarem as suas patentes militares, e referindo-se ao decreto de 18 de dezembro de 1844, escreve:

\footnotetext{
${ }^{5}$ As datas de circulação d'O Brado do Sul (09 mar. 1858-1865?) não são exatas porque as coleções não estão completas o site da Universidade de Rio Grande oferece uma listagem da Coleção Hemeroteca da Biblioteca Rio-Grandense dos jornais editados em Pelotas através do seguinte endereço http://www.dla.furg.br/ecodosul/brpel.htm e informa que a Biblioteca Nacional possui exemplares dos anos de 1859 e 1860. O Museu de Comunicação Social Hipólito José da Costa possui 172 exemplares d'OBrado do Sul dos anos de 1859,1860 e 1861, conforme a listagem publicada em: MIRANDA, 2008.

${ }^{6}$ Em Pernambuco ocorrem revoltas na capital (1831-1832) e a Guerra dos Cabanos (1832-1835) (Abreu e Lima, 1845, p.350-351). No caso de Minas Gerais em 1842 houve a prisão da maior parte dos cabeças da rebelião (Abreu e Lima, 1845, p.381). Em ambas os rebeldes foram derrotados, mortos ou presos pelas tropas imperiais.

7 "Passar-te-ia nunca pela lembrança que os respeitos e amizade que consagrei a Bento Gonçalves enquanto vivo e hoje às suas cinzas e reputação, me obrigam a desistir do histórico da revolução em que de tão boa fé tomamos tão ativa e penosa parte (...). Pois a tudo me obriga a memória desse homem, e só estudo o meio de fazê-lo com dignidade, visto a respeito ter havido o que sabes." (grifos meus) Carta de Domingos José de Almeida ao Tenente-coronel Manuel Antunes da Porciúncula. Pelotas, 17/10/1859 (CV-684). (ANAIS AHRS, 1979: 151-152, grifos meus)
} 
Lembras-te que por causa da só palavra - anistiar empregada na Proclamação do Regente foi suficiente para machucar os brios dos homens de então, sendo eu o único que a defendi na Assembleia Provincial na sustentação do parecer da comissão de que fui membro e relator, sendo, aliás, toda a redação dessa Proclamação reconhecendo, elogiando e agradecendo os relevantes serviços prestados em todas as épocas pelos rio-grandenses? (ANAIS AHRS, 1979, p.152).

Tais correspondências reiteram a vontade de alguns rio-grandenses em preservar a memória daqueles que lutaram pela república, não como rebeldes e sim como revolucionários, discussão constante entre seus defensores e opositores, explicitada na resistência dos primeiros ao termo "anistia". Em carta a Antonio Netto, Almeida propõe-se a responder às injúrias dos "pasquins infamatórios", através do seu Brado do Sul, e defender a memória "da revolução mais cavalheira do mundo e que tanto honra àqueles que a dirigiram como aos filhos do Rio Grande do Sul" levando, também, a cabo a escrita de sua história, tão logo "habilitado dos documentos e informações" necessários para tal. (ANAIS AHRS, 1979, p.147)

Existia, portanto, por parte desses homens não apenas a vontade de que essa história fosse efetivamente escrita, mas também o claro entendimento de que tal narrativa deveria ser respaldada por uma documentação que a legitimasse e se constituísse em espólio e acervo da memória da guerra, dos guerreiros e seus ideais. Nem que isso tivesse que ser feito por meio dos jornais.

Em Porto Alegre, segundo Caldre e Fião, desde 1854 havia a disposição de alguns letrados rio-grandenses em formar uma instituição para organizar a memória histórica da Província. ${ }^{8}$ O Instituto Histórico e Geográfico da Província de São Pedro (IHGPSP) torna-se uma realidade em 26 de fevereiro de 1860 na sede do Conselho Diretor da Instrução Pública, tal iniciativa, portanto já contava com o apoio das lideranças políticas locais.

Coube ao grupo reunido em torno do IHGPSP suprir a necessidade que já estava presente entre os colaboradores d'O Guayba, ou seja, a de despertar os letrados para a importância da organização e publicação dos registros sobre a história e, além disso, recuperar e coligir os dados sobre a história da Província a fim de salvar "do esquecimento os nobres procederes de seus heróis, os atos de seus homens de armas, os sucessos, os fatos políticos, civis, e industriais que sobre o belo solo desta terra se

\footnotetext{
8 Discurso proferido pelo orador, o sr. Dr. José Antonio do Valle Caldre e Fião na 1a Sessão solene aniversária de instalação. REVISTA TRIMESTRAL DO IHGPSP, março 1861, ano 2, n.1, v.2. In. (reedição) Revista do IHGRGS, n.101, I trimestre, 1946, p.67.
} 
haviam passado" ${ }^{\prime \prime}$ conforme esclarece o texto de abertura da revista apropriadamente repercutindo os ensinamentos de Heródoto. ${ }^{10}$

Essa, entretanto, não seria uma tarefa fácil, pois a reunião de forças políticas antagônicas, num espaço de preservação da memória, criaria um campo de tensões e vigília permanentes sobre qual memória seria preservada e qual história deveria ser registrada e de que maneira.

Assim a Revista do Instituto Histórico e Geográfico da Província de São Pedro foi selecionada por assinalar a constituição de um lócus privilegiado de interesse pela história local e de controle na realização de sua escrita. Entre 1860 e 1863 são publicados sete números da revista do Instituto, nos quais o que se acompanha é um grande esforço em organizar os dados relativos aos atos político-administrativos da Província, sem qualquer tipo de interpretação dessas informações apenas alguns breves comentários. São em grande parte registros, colhidos na documentação pública oficial, referentes à vida burocrática da Província. Mas aquilo sobre o que não se escreve também indica intenções.

Assim os textos relativos aos atos administrativos de fundação do Instituto bem como os discursos do presidente militar e dos letrados envolvidos no projeto de constituição de um acervo sobre a história oficial da província, testemunham sobre as pretensões, as tentativas e os atos relativos à escrita da história local, formando um proveitoso conjunto documental.

A história que os integrantes do IHGPSP deveriam narrar precisava contemplar o passado de lutas heroicas na defesa dos interesses do Império do Brasil, ressaltando o propalado patriotismo dos bravos combatentes rio-grandenses e, ao mesmo tempo, disciplinar e controlar esse passado a fim de elidir, da memória em construção, os eventos que ameaçassem o projeto político de conciliação, como a guerra civil e seus integrantes, afinal "só os seus sucessos nos tocam individualmente".

Na constituição do IHGPSP entrelaçaram-se interesses de várias ordens, entre os quais certamente um dos mais importantes era reconfigurar a imagem da Província perante o julgamento da Corte, ou seja, os homens de armas e de letras envolvidos no Instituto pretendiam demonstrar a sua capacidade de produzir glórias para o país em campos menos belicosos, embora não menos disputados. Tal disposição está explicitada no texto de apresentação do Instituto:

\footnotetext{
${ }^{9}$ REVISTA TRIMENSAL DO IHGPSP, agosto 1860, ano 1, n.1, v.1. In. (reedição) Revista do IHGRGS, n.100, IV trimestre, 1945, p.171.

10 Heródoto (Livro 1, Clio)
} 
O instituto no pé em que se acha promete muitos serviços ao país, e não será de admirar que as mais notáveis inteligências da Província busquem um lugar entre os seus membros, visto que o patriotismo sempre foi o mais belo apanágio da gente riograndense. (REVISTA do IHGRGS, n.100, 1945: 181)

Portanto compreender o Instituto e seus objetivos como um dos meios encontrados pelos letrados locais para matizar a imagem de homens de espada, ao apresentar à Corte outras possibilidades de pensar a existência regional é, sobretudo, compreender um processo que, ao impossibilitar uma efetiva escrita da história, tornou possível a criação de uma alternativa institucional e oficial de registro histórico e de produção da história regional, antes dependente do IHGB.

Nesse sentido o discurso de Caldre e Fião torna-se emblemático ao afirmar que a missão de tratar da história local cabe ao instituto regional, as palavras do orador oficial revelam o desejo de não apenas integrar a história nacional através da coleta dos documentos históricos, mas também de emitir sua própria interpretação sobre os eventos relativos à Província.

No entanto, antes de produzirem tal interpretação da história, seria necessário resolver as tensões e conflitos que se perpetuavam através das divisões políticas internas, como efeito da guerra civil. Afinal, construir uma narrativa histórica que afirmasse o leal pertencimento dos rio-grandenses ao Brasil envolvia uma delicada questão correspondente que emergia da condição de derrota que pairava sobre aqueles combatentes que a despeito de manterem suas patentes de oficiais militares, pelo Acordo de Paz assinado em Ponche Verde, foram temporariamente afastados do serviço militar. Embora passados 15 anos desde o término de um conflito, que durara uma longa década, como equacionar debaixo do mesmo discurso os interesses de exlíderes da república farroupilha com os daqueles que os combateram?

Com tais obstáculos e melindres lidavam os homens de armas e de letras envolvidos na constituição de um lugar apropriado para preservar a memória das realizações rio-grandenses e para produzir uma escrita adequada sobre feitos permeados de ambiguidades, sem contar nem mesmo com o distanciamento temporal, de fato tão profundamente marcante na vida da Província e de seus habitantes e que ainda mobilizava tão amargos sentimentos, conforme testemunham as dificuldades enfrentadas por Domingos José de Almeida na realização de sua tentativa de escrita da história.

Assim o que essa coleção de sete números da Revista do IHGPSP nos permite ver são as sucessivas tentativas dos letrados rio-grandenses em produzir um conjunto significativo de informações sobre a Província que se constituísse em acervo 
documental para a escrita da história da região e, com isso, apresentar-se como outra possibilidade de produção historiográfica.

Enquanto ideias republicanas e abolicionistas ganhavam cada vez mais adeptos integrando um conjunto maior denominado por Silvio Romero de um "bando de ideias novas"11 que alvoroçavam o horizonte da política imperial brasileira e caracterizariam a chamada geração de 1870, surge em Porto Alegre, em 1868, a Sociedade do Parthenon Litterario que inicia no ano seguinte a edição da Revista Mensal que existiria por 10 anos. ${ }^{12}$ Publicando em suas páginas tudo aquilo com que sonhara $O$ Guayba, biografias de personagens ilustres da história da Província e do Brasil, poesias, contos e romances baseados em acontecimentos da história sul-rio-grandense, e realizando em parte alguns objetivos do IHGPSP. Enfim, transformaram-se em registro histórico as memórias que invadiram as páginas dessa persistente revista, como persistentes foram as práticas letradas que possibilitaram essa transformação.

A Revista Mensal do Parthenon Litterario, destaca-se entre as demais publicações literárias sul-rio-grandenses pela duração, pelo número de colaboradores que publicaram em suas páginas (78 autores entre os quais 8 mulheres) e pelo conteúdo (em média 32 páginas por exemplar). Apesar das dissidências, mudanças de nome e das interrupções a Revista Mensal do Parthenon publicou 71 exemplares durante os anos em que esteve em circulação. Por suas páginas passaram homens, mulheres, jovens em formação e maduros letrados, os quais - alguns mais do que outros - envidaram esforços e contribuíram para o cumprimento do propósito proclamado da primeira a última série, "criar uma tribuna, para a pugna oratória", combater tenazmente na "liça da imprensa" e transpondo, insistentemente, o vocabulário do campo de batalha para a disputada arena literária, lograram substituir

\footnotetext{
11 A maior parte das categorias que compõem a formulação de Romero (Filosofia no Brasil, 1878) ainda não eram tão amplamente discutidas pelos letrados rio-grandenses, tais como: darwinismo, positivismo, spencerianismo, liberalismo, junto a esses "ismos" estavam presentes como problemas políticos-sociais o abolicionismo e o republicanismo, que indicavam questionamentos da ordem sociocultural e no limite, mudanças de práticas disseminadas e consolidadas, assim como estimulavam a criação de espaços alternativos de discussão como os periódicos literários e estabelecimento de outras redes de relação entre os grupos que constituíam "os letrados" reunidos em torno deles. Sobre as críticas dirigidas à produção de classificações teóricas estabelecidas a partir das ideias como "agentes do processo", no qual os "intelectuais" são apenas seus meros portadores ou que estes seriam "ideólogos" das ações dos "políticos" como se tais esferas de inserção social no Brasil fossem autônomas, ver Alonso, 2002. Sobre a escrita historiográfica em Silvio Romero ver Turin, 2005 e sobre as críticas ao "bando de ideias novas" ver esp. p.106-109.

\begin{abstract}
${ }^{12}$ A Revista da Sociedade do Parthenon Litterario sofre algumas alterações durante os 10 anos de sua existência. Primeiro seu nome inicia como Revista Mensal do Parthenon Litterario e depois passa a denominar-se Revista do Parthenon Litterario. A circulação também sofre algumas interrupções: em 1869 (circula de março a dezembro). Fica suspensa em 1870 e 1871. Retorna em 1872 (de julho a dezembro).Em 1873, 1874 e 1875 a circulação mensal é constante. Em 1876 é publicada de janeiro a maio. Em 1877 é publicada quinzenalmente (de agosto até outubro) e em novembro e dezembro volta a ser mensal. Não é editada em 1878, E em 1879 circula mensalmente de abril a setembro.
\end{abstract}




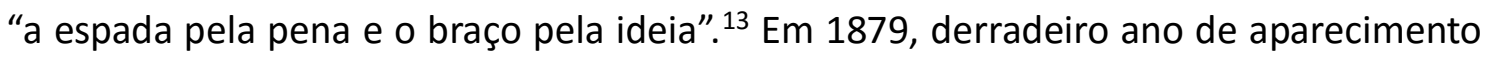
da Revista agora denominada Contemporânea, apresenta-se novamente aos leitores:

É ainda o mesmo lidador de outrora que batalha pela causa da liberdade, tendo por engenhos de guerra a palavra e a pena, e por castelo roqueiro, a escola. (Revista Contemporânea, n. 1, 1879)

A tríade palavra, pena e escola caracterizam bem as intenções de luta, as armas e a arena em que a Gendelettre do Parthenon, convertida semanticamente em Gendarme, escolheu para combater (GOMES, 2008). Entre os temas mais recorrentes estão: a escravidão tratada em poesias, romances, textos teatrais, contos; o Brasil que recebe homenagens, no Sete de setembro, com muitas poesias; assim como, a religião, a mulher, a educação e a sociedade são muito discutidas entre os partenonistas em conferências, discursos e teses.

No que concerne ao campo histórico a contribuição da Revista do Parthenon Litterario é considerável, apresentando em seu conjunto 27 biografias, 10 necrológios ou discursos fúnebres, 3 artigos e 7 poesias em homenagem a personalidades; destes, 22 biografias, 9 necrológios, 1 artigo e as 7 poesias referem-se a rio-grandenses. Fatos históricos variados que servem de tema literário comparecem nas páginas da revista, destacamos um romance ( $O$ vaqueano), dois contos (A faca dum valeiro e Um farrapo não se rende) e um poema ( $A$ evasão) que se referem a episódios da Revolução Farroupilha (respectivamente, a batalha de Laguna; o cerco de Porto Alegre; a pacificação e a fuga de Bento Gonçalves da prisão na Bahia).

Em maior número e substancialmente significativos são os artigos sobre temas históricos que aparecem sob a rubrica de Tese ou Tese histórica, das 5 teses publicadas, 2 tratam da história da Província; e exclusivamente acerca da guerra civil são os Dados Históricos sobre a Província que aparecem 10 vezes (entre correspondências, proclamações e avisos e Atas).

Tal conjunto documental oferece-nos a possibilidade de analisar o procedimento de seleção dos eventos publicados, os posicionamentos sobre a guerra civil, os personagens escolhidos para serem lembrados e ainda o tipo de interlocução existente entre as publicações, ou seja, a repercussão de ideias, argumentos ou questionamentos acerca da história sul-rio-grandense entre os sucessivos grupos de letrados nos respectivos órgãos de divulgação.

O quarto periódico ou revista literária, a juntar-se ao corpus selecionado é a Murmúrios do Guahyba - revista mensal consagrada às letras e à história da Província

\footnotetext{
${ }^{13}$ As expressões foram extraídas respectivamente do "Programa", da Revista Mensal n. 1, de 1869 e da "Introdução", da Revista Mensal n. 1, de 1872.
} 
de São Pedro do Rio Grande do Sulque circulou em Porto Alegre de janeiro a junho de 1870 , curta existência de seis exemplares com 240 páginas no total, mas suficiente para demonstrar a necessidade desses periódicos naquela sociedade e, sobretudo, por sua preocupação com a história rio-grandense.

José Bernardino dos Santos, também membro do Parthenon Litterario, era o proprietário, editor e principal redator da revista é de sua autoria a seção dedicada à história, na qual são apresentadas transcrições de documentos sobre a Revolução da Província (1835 a 1845) ou Coleção de documentos oficiais, peças autênticas e notas importantes relativas à história da revolução da Província de São Pedro do Rio Grande do Sul, títulos desta seção.

Se $O$ Guayba foi o primeiro periódico a propor um concurso de biografias, a Murmúrios do Guahyba é a primeira, na capital, a apresentar as transcrições de documentos sobre a Revolução de 1835. Atitude que é seguida pela Revista do Parthenon. Além disso, o conjunto de 5 exemplares encontrados para a pesquisa apresentam 2 artigos sobre a Guerra do Paraguai, um romance que descreve o ambiente da guerra civil e uma biografia, temas que reafirmam o interesse no registro histórico, na discussão dos efeitos da guerra e na preservação da memória dos acontecimentos.

Assim ao produzirem textos ou transcreverem documentos e iniciarem a sua publicação nos periódicos aqueles homens de letras deram início a formação de um duplo acervo documental, um relativo aos documentos publicados pertencentes a coleções públicas ou particulares e outro referente à produção periodística dedicada ao cultivo da memória e da história da Província. Tais publicações, convertidas em fonte histórica, tornam-se testemunhas da escrita pública, das escolhas de registro histórico e da existência de associações literárias sul-rio-grandenses. A sobrevivência desse conjunto documental é, portanto, representativa de um desejo de perpetuar uma memória sobre as práticas letradas da Província, demonstrando que o espaço criado para o exercício e afirmação dos letrados sul-rio-grandenses, nos periódicos literários, pode assinalar um começo institucional de produção tanto literária quanto historiográfica na Província do Rio Grande do São Pedro. ${ }^{14}$

O ofício de exumação do passado encontraria nas páginas dos periódicos literários sul-rio-grandenses o abrigo seguro para algumas memórias. O gesto dos

\footnotetext{
${ }^{14}$ Este começo - de constituição de um ambiente favorável ao florescimento de uma cultura histórica - é pensado tal como sugere Flora Süssekind (1990, p.19), a partir do arcabouço teórico de Michel Foucault sobre "origens" e "começos", visto que, em seu estudo sobre "o processo de constituição do narrador de ficção na prosa romântica brasileira", ela não pretende tratar "propriamente de "origens", mas de um "começo histórico", o do narrador de ficção no Brasil". Neste sentido, o começo histórico da formação de uma escrita da história sul-rio-grandense tem início num percurso tão descontínuo quanto persistente dos letrados reunidos em torno dos periódicos literários.
} 
letrados de darem um lugar aos seus mortos para serem lembrados equivale ao trabalho de sepultamento honroso do passado pela escrita de sua história, compreendida desse modo, a não escrita da história equivaleria a deixar os antepassados insepultos e, portanto, entregues ao esquecimento. ${ }^{15}$

Nesse sentido a memória arquivada nesses periódicos e, principalmente, na Revista do Parthenon Litterario é, em primeiro lugar, a memória das práticas letradas, em torno da escrita pública, da formação de associações literárias, do exercício do debate e da crítica, da troca de experiências, do estímulo à leitura e à troca de ideias, enfim de um espaço construído e mantido pela persistência dos jovens e dos maduros letrados rio-grandenses que, lentamente, pela reiteração dessas práticas e ao abrigo das páginas impressas transformaram desgarrados periodistas, tímidos professores, militares reformados ou na reserva e obscuros funcionários públicos em um grupo socialmente reconhecido como homens de letras, escritores e poetas que tornaram visíveis as suas ações e instituíram outro modo de manifestação cultural pelo qual os rio-grandenses poderiam ser, a partir de então, reconhecidos.

Em segundo lugar a memória da emergência da cultura histórica, sobretudo, da interdição aos eventos em torno da guerra civil e alguns de seus personagens, nesse particular, o acervo produzido pelos periódicos permite acompanhar o esforço empreendido para a realização de narrativas sobre a Revolução e a superação dos obstáculos para empreendê-las, assim surgem as primeiras publicações de transcrições de documentos originais relativos a acontecimentos da guerra civil; discussões sobre teses publicadas ou não sobre os eventos revolucionários; adoção ou rejeição de terminologias designativas aos combatentes farroupilhas, ora tratados como rebeldes ou revoltosos, ora como revolucionários ou republicanos, ou ainda como dissidentes; e as biografias que constroem modelos e padrões de comportamento, evocando o testemunho dos mortos por meio da constituição de condutas pelos memorialistas encarregados de erigi-las.

Ao efetuar a conversão dos periódicos literários em fontes históricas e considerá-los constituintes de uma instituição sociocultural capaz de formar e conferir um perfil de atuação específico aos seus integrantes, nosso gesto historiador ressignifica o que foi um meio de expressão e divulgação das ideias literárias e torna-o

15 "A escrita representa o papel de um rito de sepultamento; ela exorciza a morte introduzindo-a no discurso. Por outro lado, tem uma função simbolizadora; permite a uma sociedade situar-se, dando-lhe, na linguagem, um passado, e abrindo assim um espaço próprio para o presente: "marcar" um passado, é dar um lugar à morte, mas também redistribuir o espaço das possibilidades, determinar negativamente aquilo que está por fazer e, consequentemente, utilizar a narratividade, que enterra os mortos, como um meio de estabelecer um lugar para os vivos" (Certeau, 2002, p.106). Sobre a discussão que faz Ricoeur sobre o papel da morte na história e das formulações de Certeau ver: Ricoeur, 1997, p.194-195 e 2007 , p.373-380 
agora um lugar de práticas letradas num sentido bem mais amplo de atuação política e redimensiona ações, aparentemente isoladas, ao incluí-las numa cadeia de práticas sociais tornando-as partes escandidas do mesmo encadeamento histórico, qual seja, aquele que produz outro espaço e modo de atuação política e social para os homens da Província.

Esse é, portanto, o duplo acervo contido na memória arquivada pelos periódicos literários, cuja conservação tornou possível remontar esse quadro de práticas historiadoras entre os letrados da Província e cuja preservação também torna perceptível a intenção do monumento por trás do documento, já que o documento é parte de um monumento na medida em que ele contribui para edificar uma ideia e a ideia edificada pelo documento é o monumento que ele contém, tal como ensinam Le Goff (1996, p.548) e Ricoeur (1997, p.199).

\section{REFERÊNCIAS}

AHRS - Arquivo Histórico do Rio Grande do Sul. Anais. Vol.3. Porto Alegre: IEL, 1979.(Coleção Alfredo Varella; correspondência ativa e copiadores de Domingos José de Almeida).

ALONSO, Angela. Idéias em movimento:a geração 1870 na crise do Brasil-Império. Rio de Janeiro: Paz e Terra, 2002.

CERTEAU, Michel de. A escrita da história. Rio de Janeiro: Forense Universitária, 2002.

FIGUEIREDO, Joana Bosak de. O Rio Grande de São Pedro entre o Império do Brasil e o Prata: a identidade regional e o Estado Nacional (1851-1865). 2000. Dissertação (Mestrado em História). Universidade Federal do Rio Grande do Sul, Instituto de Filosofia e Ciências Humanas. Porto Alegre, 2000.

GOMES, Carla Renata Antunes de Souza. De rio-grandense a gaúcho: o triunfo do avesso - um processo de representação regional na literatura do século XIX (1847-1877). Porto Alegre: Ed. Associadas/SMC Prefeitura de Porto Alegre, 2009.

LE GOFF, Jacques. História e memória. Campinas: EdUNICAMP, 1996.

LIMA, José Ignácio de Abreu e. Sinopse ou dedução cronológica das fatos mais notáveis da história do Brasil. Recife: Fundação de Cultura Cidade do Recife, 1983. (Primeira edição 1845)

MENEGAT, Carla. $\mathbf{O}$ tramado, a pena e as tropas: família, política e negócios do casal Domingos José de Almeida e Bernardina Rodrigues Barcellos. (Rio Grande de São Pedro, século XIX). 2009. 
Dissertação (Mestrado em História). Universidade Federal do Rio Grande do Sul, Instituto de Filosofia e Ciências Humanas. Porto Alegre, 2009.

MIRANDA, Marcia Eckert; Leite, Carlos Roberto Saraiva da Costa. Jornais raros do MUSECOM: 1808-1924. Porto Alegre: Comunicação Impressa, 2008.

O Guayba, Periódico Semanal, Literário e Recreativo. Porto Alegre: Typographia BrasileiraAlemã, ago./ dez. 1856.

O Guayba: Periódico Semanal, Literário e Recreativo. Porto Alegre: Typographia BrasileiraAlemã, jan./dez. 1857.

Revista Mensal da Sociedade Parthenon Litterario. Porto Alegre: Typ. do Jornal do Comércio, mar./dez. 1869, ano 1. In: (reedição da 1ạ série) Revista do Instituto Histórico e Geográfico do Rio Grande do Sul. Porto Alegre: Imprensa Oficial do Estado, n.113/116, 1949. (10 exemplares) Revista Mensal da Sociedade Parthenon Litterario. Porto Alegre: Typ. Da Reforma,jul./dez. 1872. In: (reedição da 2a série) Revista do Instituto Histórico e Geográfico do Rio Grande do Sul. Porto Alegre: Imprensa Oficial do Estado, n. 117/120, 1950. (6 exemplares) Revista Mensal da Sociedade Parthenon Litterario. Porto Alegre: Litteraria, abr./ set. 1879, 4ạ série, ano 1.

Revista Trimensal do Instituto Historico e Geographico da Província de São Pedro. Porto Alegre: Typographia do Conciliador,ago. 1860, ano 1, n.1, v.1. In.: (reedição) Revista do Instituto Histórico e Geográfico do Rio Grande do Sul. Porto Alegre: Imprensa Oficial do Estado, n.100, ano 25, 4. trimestre, 1945.

Revista Trimensal do Instituto Historico e Geographico da Província de São Pedro. Porto Alegre: Typographia do Conciliador, mar. 1861, ano 2, n.1, v.2. In: (reedição) Revista do Instituto Histórico e Geográfico do Rio Grande do Sul. Porto Alegre: Imprensa Oficial do Estado, n.101, ano 25, 4.trimestre, 1945 (ou I trimestre, 1946). ${ }^{16}$

RICOEUR, Paul. A memória, a história, o esquecimento. Campinas: EdUNICAMP, 2007. .Tempo e narrativa:tomo III. Campinas: Papirus, 1997.

SILVA, Jandira M. M.;Clemente, Elvo;Barbosa, Eni. Breve histórico da imprensa sul-riograndense. Porto Alegre: CORAG, 1986.

16 Este exemplar da Revista do IHGRS informa duas datas diferentes: I Trimestre de 1946 (capa) e IV Trimestre de 1945 na parte interna. 
SÜSSEKIND, Flora. O Brasil não é longe daqui: o narrador, a viagem. São Paulo: Cia. das Letras, 1990.

TURIN, Rodrigo. Narrar o passado, projetar o futuro: Sílvio Romero e a experiência historiográfica Oitocentista. 2005. Dissertação (Mestrado em História). Universidade Federal do Rio Grande do Sul, Instituto de Filosofia e Ciências Humanas. Porto Alegre, 2005. 